\title{
Fertility of mice receiving vitrified adult mouse ovaries
}

\author{
Toshio Hani, Takanori Tachibe, Saburo Shingai, Nobuo Kamada, Otoya Ueda \\ and Kou-ichi Jishage \\ Chugai Research Institute for Medical Science, Inc., 1-135 Komakado, Gotemba, Shizuoka, 412-8513 Japan \\ Correspondence should be addressed to Kou-ichi Jishage; Email: jishagekui@chugai-pharm.co.jp
}

\begin{abstract}
Cryopreservation of the ovaries is a useful technology for preservation of germ cells from experimental animals, because if the female founder is infertile or has mutated mitochondrial DNA, preservation of female germ cells is necessary. Although it is possible to cryopreserve immature mouse ovaries with a high degree of viability by vitrification with a mixture of several cryoprotectants, the viability of cryopreserved adult mouse ovaries is still unknown. Here, we investigated the viability of mouse ovaries at various ages after cryopreservation by vitrification techniques. Donor ovaries were collected from 10-day-, 4-week-, 10-week- and 7-month-old, female, nulliparous, green fluorescence protein (GFP)-transgenic mice and cryopreserved by vitrification. The vitrified-warmed ovaries were orthotopically transplanted to 4- or 10-week-old mice. GFP-positive pups were obtained in all experimental groups. In the 4-week-old recipients, the percentages of GFP-positive pups among the total pups from recipients transplanted with ovaries of 10-day-, 4-week-, 10-week- and 7-month-old donors were $44 \%, 9 \%, 12 \%$ and $4 \%$ respectively. In the 10 -week-old recipients, the percentages of GFP-positive pups among the total pups from recipients transplanted with ovaries of 10 -day-, 4-week-, 10-week- and 7-month-old donors were $36 \%, 16 \%, 2 \%$ and $9 \%$ respectively. Furthermore, GFP-positive pups also were obtained from recipients transplanted with ovaries of donors without normal estrous cyclicity. Our results indicate that cryopreservation of mouse ovaries by vitrification is a useful method for the preservation of female germ cells from mice of various ages.

Reproduction (2006) 131 681-687
\end{abstract}

\section{Introduction}

Mutant or transgenic animals occasionally suffer from infertility. Therefore, the preservation of germ cells is a useful technology for maintenance or propagation of the experimental animal lines. Cryopreservation of spermatozoa, of which a large number from a few males are easily preserved, has been widely used to archive mouse strains (Okamoto et al. 1988, Nakagata et al. 1996, Nakagata et al. 1997). For reproduction, it is necessary to preserve female germ cells as well if the female founder is infertile or has mutated mitochondrial DNA (Inoue et al. 2002, Silva \& Larsson 2002). Although the preservation of female germ cells and mitochondrial DNA can be accomplished through egg preservation, preservation of immature oocytes is the most effective method for those animals that do not respond to hormonal stimulation or that die unexpectedly. However, the oocyte-granulosa cell complex is required for the growth and maturation of oocytes (Richards et al. 1987, Matzuk et al. 2002). Therefore, it is necessary to preserve the ovaries and/or follicles and maintain their structure.
Ovaries from young mice that have been dissected and halved are cryopreserved by either the equilibrium freezing method (Cox et al. 1996, Gunasena et al. 1997, Sztein et al. 1998, 1999, Candy et al. 2000, Shaw \& Trounson 2002) or the vitrification method (Kagabu \& Umezu 2000, Takahashi et al. 2001, Migishima et al. 2003). Recently, a new cryopreservation method for 10-day-old mouse ovaries by vitrification was reported (Migishima et al. 2003) using DAP213 (Nakagata 1989), a combination of the cryoprotectants dimethyl sulfoxide (DMSO), acetamide and propanediol in concentrations of 2, 1 and $3 \mathrm{~mol} / \mathrm{l}$ respectively. It is the first report on the vitrification of whole ovaries. Additionally, this method has had a high success rate in mouse production via ovary transplantation. However, the viability of vitrified-warmed adult mouse ovaries is still unknown for this method.

In the present study, we investigated the viability of mouse ovaries of various ages after vitrification and the potential of this technology as a method for the preservation of female germ cells. 


\section{Materials and Methods}

\section{Donor ovaries}

Donor ovaries were collected from 10-day-, 4-week-, 10-week- and 7-month-old, female, nulliparous, green fluorescence protein (GFP)-transgenic mice (genetic background: $\mathrm{C} 57 \mathrm{BL} / 6 \mathrm{~J} \mathrm{JCl})$. Donor ovaries were aseptically placed in disposable Petri dishes containing Whitten's medium (Whitten 1971). Vaginal smear samples were taken from all 7-month-old donor mice daily for 7 days before donation to determine their estrous cyclicity. Vaginal cell specimens were spotted onto glass slides by gently pipetting with a small amount of water and left to dry for a few minutes. After Giemsa staining, the specimens were classified into one of the following four categories: 1. proestrous, 2. estrous, 3. metoestrous and 4. diestrous. Seven-month-old donor mice that were classified as diestrous during their estrous cyclicity were regarded as donor mice without normal estrous cyclicity.

\section{Ovary cryopreservation and warming}

Ovaries isolated from the 4-week-, 10-week- and 7-month-old mice were cut into fourths (about $1 \mathrm{~mm}^{3}$ ) to approximate the size of the ovaries of a 10-day-old mouse (Fig. 1). The ovaries were cryopreserved by vitrification with DAP213 (2 mol/l DMSO, $1 \mathrm{~mol} / \mathrm{l}$ acetamide and $3 \mathrm{~mol} / \mathrm{l}$ propanediol in PBI medium (Whittingham 1974)), as described by Migishima et al. (2003). Isolated ovaries were pretreated with $40 \mu \mathrm{l}$ of $1 \mathrm{~mol} / \mathrm{I}$ DMSO in PBI medium at room temperature for $5 \mathrm{~min}$. This step was repeated twice. The ovaries were then transferred into $1 \mathrm{ml}$ cryotubes (Nalge Nunc International KK, Tokyo, Japan) containing $5 \mu \mathrm{l}$ of $1 \mathrm{~mol} / \mathrm{l}$ DMSO in $\mathrm{PBI}$ medium. The cryotubes were placed in a $0^{\circ} \mathrm{C}$ Labtop cooler
(Nalge Nunc International KK, Tokyo, Japan) for $5 \mathrm{~min}$. Then $95 \mu \mathrm{l}$ DAP2 13 kept at $0^{\circ} \mathrm{C}$ were added to each cryotube, and the cryotubes were placed in the $0^{\circ} \mathrm{C}$ Labtop cooler for $5 \mathrm{~min}$. After exposure to DAP213, the cryotubes were plunged directly into liquid nitrogen and stored. For warming, cryotubes containing the samples kept in liquid nitrogen were diluted with $\mathrm{PBI}$ medium containing $0.25 \mathrm{~mol} / \mathrm{l}$ sucrose kept at $37^{\circ} \mathrm{C}$. The recovered ovaries were transferred to the $\mathrm{PBI}$ medium for washing twice and then transferred to Whitten's medium before transplantation.

\section{Ovary transplantation}

Fresh or vitrified-warmed isolated ovaries were transplanted into 4- or 10-week-old female non-GFP C57BL/6 Jcl mice (CLEA Japan, Tokyo, Japan) by the transplantation procedure described by Migishima et al. (2003). Briefly, recipients were anesthetized with $10 \%$ sodium pentobarbital (Dainippon Pharmaceutical Co., Osaka, Japan) by i.p. injection. A single transverse incision of the skin at the dorsal, across the lumber area, gave access to the ovaries on both sides. A small slit was made in the fat surrounding the ovarian bursa to expose the ovary. Half of the recipient's ovarian tissues were removed and a fresh or a vitrified-warmed ovary from a donor mouse was orthotopically transplanted into the respective ovarian bursa of a non-GFP recipient. Then, the small slit in the fat surrounding the ovarian bursa was closed by applying pressure with tweezers. One of the ovaries from a 10-dayold donor mouse was orthotopically transplanted into the respective ovarian bursa of a non-GFP recipient. Each quarter piece of ovary, from the 4-week-, 10-week- and 7-month-old donor mice was orthotopically transplanted into the respective ovarian bursa of non-GFP recipients.

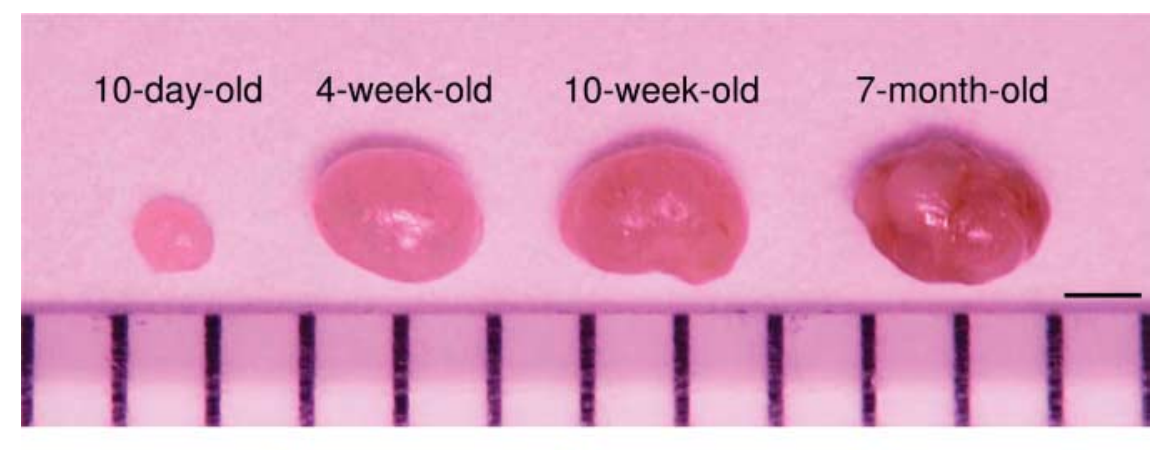

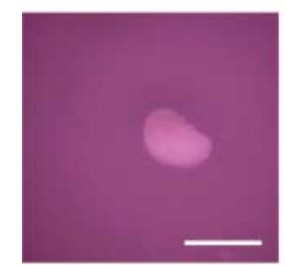

10-day-old

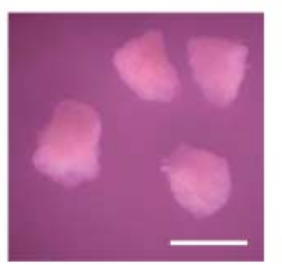

4-week-old

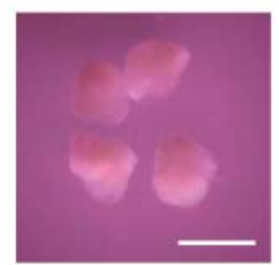

10-week-old

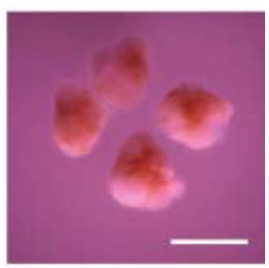

7-month-old

Figure 1 Ovaries of GFP-transgenic mice at various ages. Ovaries isolated from 4-week-, 10-week- and 7-month-old mice were cut into fourths (about $1 \mathrm{~mm}^{3}$ ), similar to the size of the ovaries of a 10-day-old mouse, to approximate the same permeation by DAP213. Bars: $1 \mathrm{~mm}$. 
The ovarian complex was replaced in the body cavity, and the incision was closed with wound clips (auto clip $9 \mathrm{~mm}$; Nihon Becton Dickinson, Tokyo, Japan). Three weeks after ovary transplantation, the recipient mice were mated with C57BL/6J JCl mice. Recipients in whom pregnancy was not detected during 8 weeks of pairing were regarded as infertile. The numbers of total pups, live pups and pups from donor ovaries that showed green fluorescence under ultraviolet light were counted.

\section{Statistical analyses}

Data presented in this study were analyzed statistically by the chi-square test and Tukey test for nonparametric multiple comparisons. In all statistical tests, a difference was considered significant when the two-tailed $P$ value was $<0.05$.

All mice were housed in a controlled environment of light/dark (light 0500-1900 h), temperature $\left(24 \pm 1^{\circ} \mathrm{C}\right.$ ), and humidity $(50 \% \pm 10 \%)$ with free access to standard laboratory chow (CE-2; CLEA Japan). The Animal Care and Use Committee of Chugai Pharmaceutical (Shizuoka, Japan) reviewed the protocols and confirmed that the animals used in the present study were cared for and used humanely.

\section{Results}

\section{Fertility of recipients transplanted with fresh donor ovaries}

All recipients transplanted with fresh ovaries gave birth to live pups with an average litter size normal for nontreated C57BL/6J Jcl mice (Table 1). Additionally, all of the experimental groups showed GFP-positive pups. The percentage of GFP-positive pups among the total pups delivered from 4-week-old recipients transplanted with ovaries from 4-week-old donors (61\%) was significantly higher than that of 10-week-old recipients transplanted with ovaries from 4-week-old donors (22\%). There was no significant difference between the percentages of GFP-positive pups among the total pups delivered from 4- and 10-week-old recipients transplanted with ovaries from 10-week- or 7-month-old donors. For two of the ten 7-month-old donors, estrous cyclicity was not observed for at least 7 consecutive days from the vaginal smear test. GFP-positive pups were born to one of the two 4-week-old recipients and to the two 10-week-old recipients transplanted with ovaries from 7-month-old donors without normal estrous cyclicity.

The reproductive efficiency for the various combinations of recipient age and donor age was calculated by the following formula: reproductive efficiency $=$ no. of GFP-positive pups / no. of donor mice used for transplantation. The reproductive efficiency of 4-week-old recipients transplanted with ovaries from 4-week-old donors (18.2) was nearly threefold higher than that of the 10-week-old recipients transplanted with ovaries from 4-weekold donors (6.4) (Fig. 2). The reproductive efficiency of 4-week-old recipients transplanted with ovaries from 10-week-old donors (15.1) was similar to the reproductive efficiency of 10-week-old recipients transplanted with ovaries from 10-week-old donors (13.1).

All recipients delivered GFP-positive pups for three litters. The cumulative GFP-positive pup birthrate including the third litter from recipients transplanted with the ovaries from 10-day-, 10-week- and 7-month-old donors showed similar rates for 4- and 10-week-old recipients (Fig. 3). GFP-positive pup birthrate per litter of 4-week-old recipients transplanted with ovaries from 4-week-old donors maintained a rate higher than that of 10-week-old recipients transplanted with ovaries from 4-week-old donors.

\section{Fertility of recipients transplanted with vitrified- warmed donor ovaries}

The percentage of impregnated recipients and the average litter size were not significantly different between

Table 1 Viability of transplanted fresh ovaries.

\begin{tabular}{|c|c|c|c|c|c|c|c|}
\hline \multicolumn{2}{|c|}{ Experimental group } & \multirow[b]{2}{*}{ Recipients no. } & \multirow{2}{*}{$\begin{array}{c}\text { Preganancies } \\
\text { no. }(\%)\end{array}$} & \multirow{2}{*}{$\begin{array}{c}\text { Recipients bearing } \\
\text { GFP-positive pups } \\
\text { no. }(\%) *\end{array}$} & \multirow{2}{*}{$\begin{array}{c}\text { Pups born } \\
\text { total no. }\end{array}$} & \multirow{2}{*}{$\begin{array}{l}\text { Average } \\
\text { litter size }\end{array}$} & \multirow{2}{*}{$\begin{array}{c}\text { GFP-positive pups } \\
\text { among pups born } \\
\text { no. }(\%) * *\end{array}$} \\
\hline Donor & Recipient & & & & & & \\
\hline 10-day-old & \multirow{4}{*}{ 4-week-old } & 6 & $6(100)$ & $6(100)$ & 42 & 7.0 & $35(83)^{\text {all }}$ \\
\hline 4-week-old & & 14 & $14(100)$ & $13(93)$ & 96 & 6.9 & $59(61)^{\mathrm{ab}} \iint$ \\
\hline 10-week-old & & 15 & $15(100)$ & $15(100)$ & 101 & 6.7 & $55(54)^{b}$ \\
\hline 7-month-old & & 10 & $10(100)$ & 7 (70) & 55 & 5.5 & $10(18)^{\mathrm{C}}$ \\
\hline 10-day-old & \multirow{4}{*}{ 10-week-old } & 5 & 5 (100) & 5 (100) & 26 & 5.2 & $14(54)^{\mathrm{abd} \|}$ \\
\hline 4-week-old & & 20 & $20(100)$ & $15(75)$ & 143 & 7.2 & $31(22)^{\mathrm{C}} \iint$ \\
\hline 10-week-old & & 14 & $14(100)$ & $13(93)$ & 109 & 7.8 & $46(42)^{\mathrm{bd}}$ \\
\hline 7-month-old & & 10 & $10(100)$ & $8(80)$ & 73 & 7.3 & $22(30)^{\mathrm{cd}}$ \\
\hline
\end{tabular}

Fresh ovaries were transplanted into a recipient, grafted into the respective ovarian bursa.

*Calculated from the number of pregnant recipients.

$* *$ Calculated from the number of pups born.

a,b,c,d Significiant difference $(P<0.05)$ by Tukey's test.

Values with different superscripts are significantly different in the same parameter and recipient age.

II, sf Significantly different $(P<0.05)$ by chi-square test. 


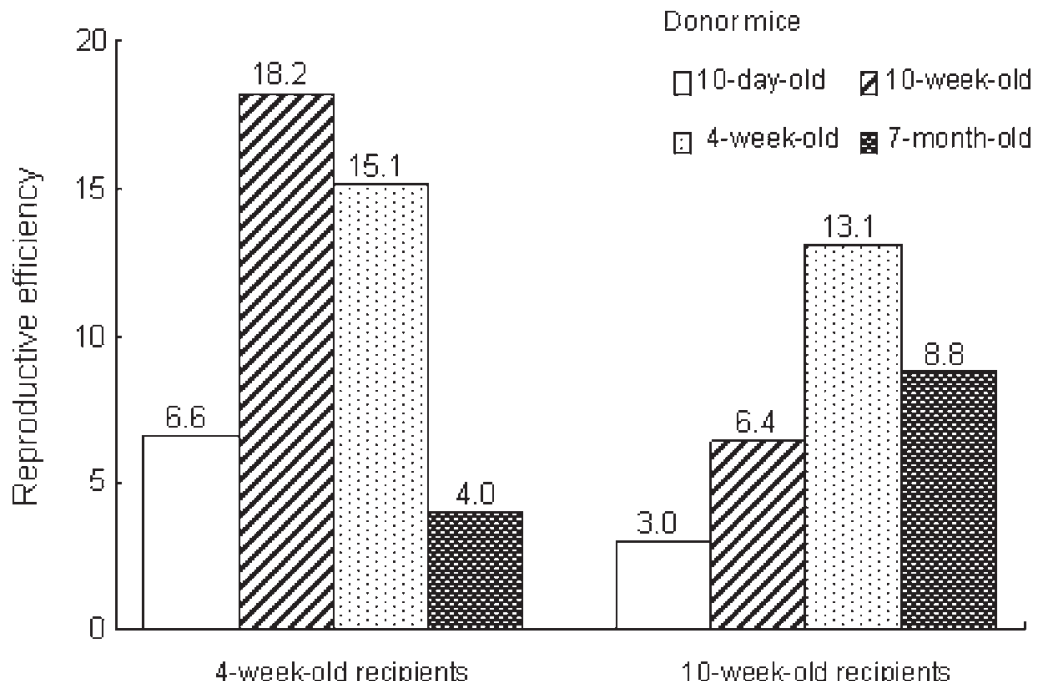

Figure 2 Reproductive efficiency in mice with fresh ovary transplantation. Reproductive efficiency was based on the number of GFP-positive pups from a recipient's first delivery and calculated by the formula previously given. In 4-week-, 10-week- and 7-month-old donors, four recipients were used per donor mouse. Infertile recipients were included in the total number of recipients. experimental groups of vitrified-warmed donor ovaries (Table 2). GFP-positive pups were obtained in all experimental groups. Additionally, the percentage of GFP-positive pups among the total pups delivered did not significantly differ for either 4- or 10-week-old recipients among all ages of donors tested. No estrous cyclicity was observed for at least 7 consecutive days in the vaginal smear test in two of the ten 7-month-old donors. GFP-positive pups were born to one of the two 10-weekold recipients transplanted with the ovaries from 7-month-old donors without normal estrous cyclicity.

The reproductive efficiency of the vitrified-warmed donors was calculated by the same equation as for fresh donors. The reproductive efficiency was not greatly different among recipients transplanted with ovaries from all ages tested (Fig. 4).
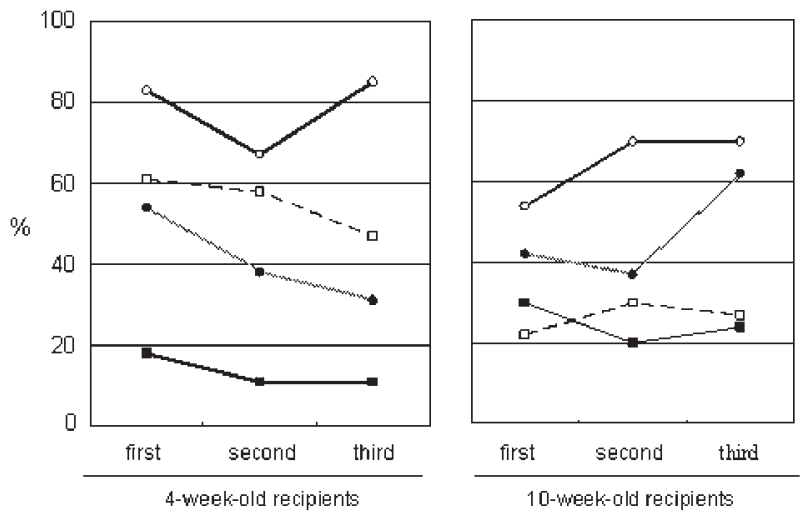

GFP-positive pups per litter

Figure 3 GFP-positive pup birthrate per three litters of recipients transplanted with fresh ovaries. GFP-positive pup birthrate for recipients transplanted with fresh ovaries from 10-day- $(O)$, 4-week- $(\square)$,

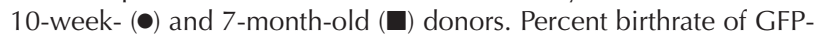
positive pups $=$ (no. of GFP-positive pups / total no. of pups born) $\times 100$.
With the exception of recipients transplanted with ovaries from 10-day-old donors, the GFP-positive pup birthrate decreased greatly after the second litter (Fig. 5).

\section{Discussion}

The birth of live offspring after orthotopic transplantation of frozen-thawed mouse ovarian tissues has been widely reported (Cox et al. 1996, Gunasena et al. 1997, Sztein et al. 1998, 1999, Candy et al. 2000, Takahashi et al. 2001, Shaw \& Trounson 2002, Migishima et al. 2003), and the technology of vitrification is expected to be useful for the simple and rapid preservation of female germ cells in experimental animals. However, only a limited number of reports on the birth of live offspring after transplantation of ovaries cryopreserved by vitrification have been published (Takahashi et al. 2001, Migishima et al. 2003) compared with reports on the equilibrium freezing method (Cox et al. 1996, Gunasena et al. 1997, Sztein et al. 1998, 1999, Candy et al. 2000, Shaw \& Trounson 2002). Moreover, there has been only one report on successful cryopreservation by vitrification of adult mouse ovaries (Takahashi et al. 2001). For the experiments of Takahashi and his colleagues, the vitrification method of Rall and Fahy (1985) with VS1, a combination of the cryoprotectants 20.5\% (w/v) DMSO, 15.5\% (w/v) acetamide, 10\% $(\mathrm{w} / \mathrm{v})$ propylene glycol and $6 \%(\mathrm{w} / \mathrm{v})$ polyethylene glycol was used. However, this method requires many steps of vitrification and warming. DAP213 was developed from VS1 in order to simplify the procedure of vitrification for mouse oocytes and embryos. Although the toxicity of DAP213 in ovarian cells is unknown, a high degree of viability after orthotopic transplantation of cryopreserved immature mouse ovaries by vitrification with DAP213 has been reported (Migishima et al. 2003). In using this vitrification method to preserve germ cells, it is important to estimate the viability of cryopreserved adult mouse ovaries. If cryopreservation of adult mouse ovaries by 
Table 2 Viability of transplanted vitrified-warmed ovaries.

\begin{tabular}{|c|c|c|c|c|c|c|c|}
\hline \multicolumn{2}{|c|}{ Experimental group } & \multirow[b]{2}{*}{ Recipients no. } & \multirow{2}{*}{$\begin{array}{l}\text { Preganancies } \\
\text { no. }(\%)\end{array}$} & \multirow{2}{*}{$\begin{array}{c}\text { Recipients bearing } \\
\text { GFP-positive pups } \\
\text { no. }(\%)^{*}\end{array}$} & \multirow{2}{*}{$\begin{array}{l}\text { Pups born } \\
\text { total no. }\end{array}$} & \multirow{2}{*}{$\begin{array}{l}\text { Average } \\
\text { litter size }\end{array}$} & \multirow{2}{*}{$\begin{array}{c}\text { GFP-positive pups } \\
\text { among pups born } \\
\text { no. }(\%)^{* *}\end{array}$} \\
\hline Donor & Recipient & & & & & & \\
\hline $\begin{array}{l}\text { 10-day-old } \\
\text { 4-week-old } \\
\text { 10-week-old } \\
7 \text {-month-old }\end{array}$ & 4-week-old & $\begin{array}{r}5 \\
13 \\
12 \\
10\end{array}$ & $\begin{aligned} 5 & (100) \\
13 & (100) \\
10 & (83) \\
8 & (80)\end{aligned}$ & $\begin{array}{l}4(80) \\
6(46) \\
4(40) \\
2(25)\end{array}$ & $\begin{array}{l}32 \\
79 \\
67 \\
55\end{array}$ & $\begin{array}{l}6.4 \\
6.1 \\
6.7 \\
6.9\end{array}$ & $\begin{aligned} 14 & (44)^{\mathrm{a}} \\
& 7(9)^{\mathrm{b}} \\
8 & (12)^{\mathrm{bc}} \\
2 & (4)^{\mathrm{b}}\end{aligned}$ \\
\hline $\begin{array}{l}\text { 10-day-old } \\
\text { 4-week-old } \\
\text { 10-week-old } \\
7 \text {-month-old }\end{array}$ & 10-week-old & $\begin{array}{r}5 \\
13 \\
10 \\
9\end{array}$ & $\begin{aligned} 5 & (100) \\
11 & (85) \\
9 & (90) \\
5 & (56)\end{aligned}$ & $\begin{array}{l}3(60) \\
5(45) \\
1(11) \\
2(40)\end{array}$ & $\begin{array}{l}25 \\
64 \\
63 \\
33\end{array}$ & $\begin{array}{l}5.0 \\
5.8 \\
7.0 \\
6.6\end{array}$ & $\begin{aligned} 9 & (36)^{\mathrm{ac}} \\
10 & (16)^{\mathrm{ab}} \\
1 & (2)^{\mathrm{b}} \\
3 & (9)^{\mathrm{bc}}\end{aligned}$ \\
\hline
\end{tabular}

Vitrified-warmed ovaries were transplanted into a recipient and grafted into the respective ovarian bursa.

*Calculated from the number of pregnant recipients.

** Calculated from the number of pups born.

a,b,c Significant difference $(P<0.05)$ by Tukey's test.

Values with different superscripts are significantly different in the same parameter and recipient age.

vitrification is successful, it would be a valuable technology not only for reproduction, but also for archiving female germ cells and maintaining endangered mouse strains. In the present study, we compared the viability of cryopreserved adult mouse ovaries with that of immature ovaries. Our results indicate that adult as well as immature mouse ovaries cryopreserved by vitrification with DAP213 are viable for producing young. Further studies are necessary to investigate the effects from the number of donor ovaries transplanted into a recipient and the amount of cryoprotectant remaining in the ovarian tissue on the fertility of mice receiving donor ovaries.

Although GFP-positive pups were obtained from all vitrified-warmed donor ovaries examined in this study, the percentages of GFP-positive pups among the total pups delivered from recipients were lower than from fresh ovaries in all combinations of recipient age and donor age (Tables 1 and 2). These data indicate that vitrification and warming the ovaries reduced their viability, consistent with the results Migishima et al. (2003) reported, using ovaries from 10-day-old, immature mice as grafts. This tendency showed especially when 4-week-, 10-week- and 7-month-old mice were used as donors (Tables 1 and 2). It is possible that the wide range of developmental stages of follicles in adult mouse ovaries is one of the causes of this tendency. Previous reports describing ovarian histology after freeze-thawing concluded that large mature follicles are more affected by freezing injuries and small immature follicles have a higher survival rate (Parrot 1960, Smith 1961, Gosden 1992, Harp et al. 1994, Cox et al. 1996, Candy et al. 1997). The number of large follicles that survive after freeze-thawing has been estimated to be about $5 \%$ of the total surviving follicles (Green et al. 1956). Additionally, analysis of the effect of cryoprotectants on follicle survival after freezing demonstrated that $81-94 \%$ of primordial follicles survived when DMSO was used as the cryoprotectant (Candy et al. 1997). In spite of a reduction in the number of donor-derived pups, the present results indicate that follicles in adult mouse ovaries are viable even after vitrification and develop normally

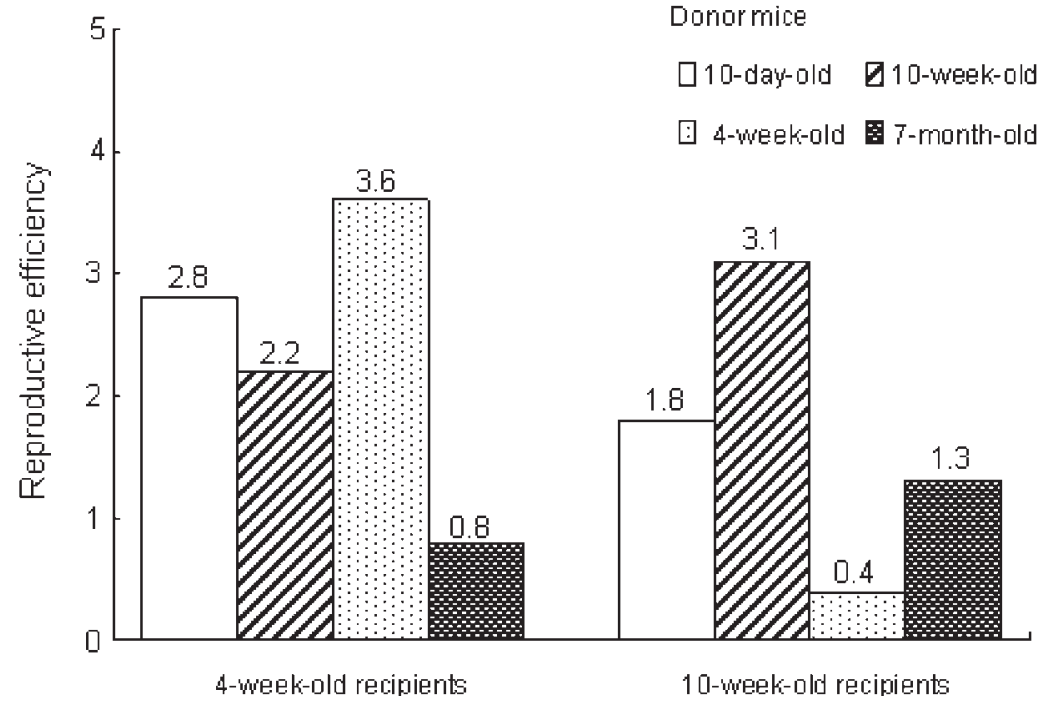

www.reproduction-online.org
Figure 4 Reproductive efficiency in mice with frozen-thawed ovary transplantation. Reproductive efficiency was based on the number of GFPpositive pups from a recipient's first delivery and calculated by the formula previously given. In 4-week-, 10-week- and 7-month-old donors, four recipients were used per donor mouse. Infertile recipients were included in the total number of recipients. 

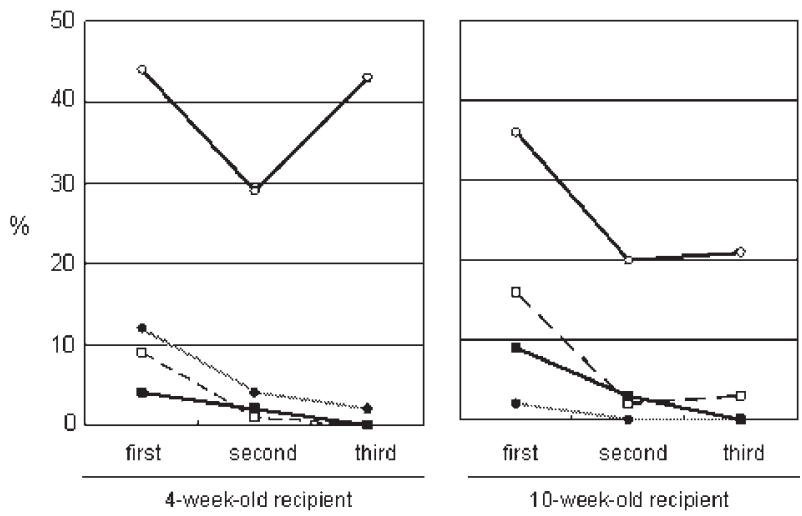

GFP-positive pups per litter

Figure 5 GFP-positive pup birthrate per three litters of recipients transplanted with frozen-thawed ovaries. GFP-positive pup birthrate for recipients transplanted with frozen-thawed ovaries from 10-day$(\bigcirc)$, 4-week- $(\square)$, 10-week- $(\bullet)$ and 7-month-old (ם) donors. Percent birthrate of GFP-positive pups = (no. of GFP-positive pups / total no. of pups born) $\times 100$.

after orthotopic transplantation into recipients. Additionally, GFP-positive pups were born to recipients transplanted with ovaries from 7-month-old donors without normal estrous cyclicity for at least 7 consecutive days, whether the ovaries of donors were fresh or cryopreserved. Therefore, it seems that follicles in ovaries from mice without normal estrous cyclicity also have the capability to develop normally even after vitrification and warming. However, further studies are required to elucidate the involvement of estrous cyclicity.

The most efficient reproduction was observed in 4-week-old recipients transplanted with fresh ovaries from 4-week-old donors with an efficiency rate nearly threefold higher than that of 10-week-old recipients transplanted with fresh ovaries from 4-week-old donors (Fig. 2). However, there was no significant difference in reproductive efficiency between 4- and 10-week-old recipients transplanted with fresh ovaries from 10-week-old donors. In recipients transplanted with fresh ovaries from 10-day- and 4-week-old donors, the percentage of GFP-positive pups among the total pups delivered from 4-week-old recipients was significantly higher than from 10-week-old recipients (Table 1). Additionally, GFP-positive pup birthrate per three litters of 4-week-old recipients transplanted with fresh ovaries from 4-week-old donors maintained a rate higher than that of 10-week-old recipients transplanted with fresh ovaries from 4-week-old donors. And recipients transplanted with ovaries from 10-day-, 10-week- and 7-month-old donors had almost the same birthrate whether the recipients were 4- or 10-week-old mice (Fig. 3). This suggests that 10-week-old recipients may have some negative effects on fresh ovarian grafts from 10-day- and 4-week-old donors. Thus, 4-week-old mice would be more suitable recipients for producing young via fresh ovary transplantation.
The above-mentioned negative effects of fresh ovarian grafts of young mice were not seen in 10-week-old recipients transplanted with vitrified-warmed ovaries (Fig. 4). Migishima et al. (2003) reported no difference between the percentages of donor ovarian oocytes among total oocytes collected from recipients transplanted with fresh ovaries and recipients transplanted with vitrified-warmed ovaries; however, the number of oocytes collected per recipient transplanted with vitrified-warmed ovaries was about one-third that per recipient transplanted with fresh ovaries. If the ovaries of donors are affected by cryopreserving injuries, the percentage of donor ovarian oocytes of total oocytes collected from recipients transplanted with vitrifiedwarmed ovaries would be lower than from recipients transplanted with fresh ovaries. Thus, cryoprotectants remaining in the ovarian tissue after warming and washing might have some effect on the recipients locally or systemically as well as on the viability of the graft itself. The reduced pregnancy rate for recipients with vitrified-warmed ovaries may also have been a result of such effects (Table 2).

Both adult and immature mouse ovaries cryopreserved by vitrification with DAP213 are viable for producing young, and follicles in ovaries of adult mice without normal estrous cyclicity also have the capability to develop normally even after vitrification and warming. Our results indicate that cryopreservation of mouse ovaries by vitrification with DAP213 is a useful method for preservation of female germ cells from mice at various ages. However, after a second litter, few pups were delivered from ovaries of donors from recipients transplanted with vitrified-warmed ovaries from adult mice. Further studies are necessary to improve ovary cryopreservation by vitrification in order.

\section{Acknowledgements}

We thank S Uchida for providing excellent technical assistance, $\mathrm{H}$ Tateishi for breeding the mice, $\mathrm{Y}$ Kawase and $\mathrm{M}$ Koto for their helpful comments, and Ms F Ford for proofreading the manuscript. The authors declare that there is no conflict of interest that would prejudice the impartiality of this scientific work.

\section{References}

Candy CJ, Wood MJ \& Whittingham DG 1997 Effect of cryoprotectants on the survival of follicles in frozen mouse ovaries. Journal of Reproduction and Fertility 110 11-19.

Candy CJ, Wood MJ \& Whittingham DG 2000 Restoration of a normal reproductive life span after grafting of cryopreserved mouse ovaries. Human Reproduction 15 1300-1304.

Cox SL, Shaw JM \& Jenkin G 1996 Transplantation of cryopreserved fetal ovarian tissue to adult recipients in mice. Journal of Reproduction and Fertility 107 315-322.

Gosden RG 1992 Transplantation of fetal germ cells. Journal of Assisted Reproduction and Genetics 9 118-123. 
Green SH, Smith AV \& Zukermans S 1956 The number of oocytes in ovarian autografts freezing and thawing. Journal of Endocrinology $13330-334$

Gunasena KT, Villines PM, Critser ES \& Critser KJ 1997 Live births after autologous transplant of cryopreserved mouse ovaries. Human Reproduction 12 101-106.

Harp R, Leibach J, Black J, Keldahl C \& Karow A 1994 Cryopreservation of murine ovarian tissue. Cryobiology 31 336-343.

Inoue K, Ogura A \& Hayashi J 2002 Production of mitochondrial DNA transgenic mice using zygotes. Methods 26 358-363.

Kagabu S \& Umezu M 2000 Transplantation of cryopreserved mouse, Chinese hamster, rabbit, Japanese monkey and rat ovaries into rat recipients. Experimental Animals 49 17-21.

Matzuk MM, Burns KH, Viveiros MM \& Eppig JJ 2002 Intercellular communication in the mammalian ovary: oocytes carry the conversation. Science 296 2178-2180.

Migishima F, Suzuki-Migishima R, Song SY, Kuramochi T, Azuma S, Nishijima M \& Yokoyama M 2003 Successful cryopreservation of mouse ovaries by vitrification. Biology of Reproduction 68 881-887.

Nakagata N 1989 High survival rate of unfertilized mouse oocytes after vitrification. Journal of Reproduction and Fertility 87 479-483.

Nakagata N 1996 Use of cryopreservation techniques of embryos and spermatozoa for production of transgenic (Tg) mice and for maintenance of Tg mouse lines. Laboratory Animal Science $\mathbf{4 6}$ 236-238.

Nakagata N, Okamoto M, Ueda O \& Suzuki H 1997 Positive effect of partial zona pellucida dissection on the in vitro fertilizing capacity of cryopreserved C57BL/6J transgenic mouse spermatozoa of low motility. Biology of Reproduction 57 1050-1055.

Okamoto M, Nakagata N, Ueda O, Kamada N \& Suzuki H 1988 Cryopreservation of gene disrupted mouse spermatozoa. Journal of Mammalian Ova Research 15 77-88.

Parrot DM 1960 The fertility of mice with orthotopic ovarian grafts derived from frozen tissue. Journal of Reproduction and Fertility $\mathbf{1}$ 230-241.

Rall WF \& Fahy GM 1985 Ice-free cryopreservation of mouse embryo at -196 degrees $C$ by vitrification. Nature 313 573-575.
Richards JS, Jahnsen T, Hedin L, Lifka J, Ratoosh S, Durica JM \& Goldring NB 1987 Ovarian follicular development: from physiology to molecular biology. Recent Progress in Hormone Research $43231-270$.

Shaw JM \& Trounson AO 2002 Ovarian tissue transplantation and cryopreservation. Application to maintenance and recovery of transgenic and inbred mouse lines. In Transgenesis Techniques: Principles and Protocols, 2nd edn, Methods in Molecular Biology pp 229-251. Ed. AR Clarke. Totowa, NJ: Humana Press.

Silva JP \& Larsson NG 2002 Manipulation of mitochondrial DNA gene expression in the mouse. Biochimica et Biophysica Acta 1555 106-110.

Smith AU 1961 The viability of the frozen ovarian tissue. In Biological Effects of Freezing and Supercooling, pp 166-196. Eds. H Barcroft, H Davinson \& WDM Paton, London: Arnold.

Sztein JM, Sweet H, Farley J \& Mobraaten LE 1998 Cryopreservation and orthotopic transplantation of mouse ovaries: new approach in gamete banking. Biology of Reproduction 58 1071-1074.

Sztein JM, McGregor TE, Bedigian HJ \& Mobraaten LE 1999 Transgenic mouse strain rescue by frozen ovaries. Laboratory Animal Science 49 99-100.

Takahashi E, Miyoshi I \& Nagasu T 2001 Rescue of a transgenic mouse line by transplantation of a frozen-thawed ovary obtained postmortem. Contemporary Topics in Laboratory Animal Science $4028-31$.

Whitten WK 1971 Embryo medium. Nutrient requirements for the culture of preimplantation embryos in vitro. Advances in the Biosciences 6 129-141.

Whittingham DG 1974 Embryo banks in the future of developmental genetics. Genetics 78 395-402.

Received 2 November 2005

First decision 14 December 2005

Revised manuscript received 11 January 2006

Accepted 16 January 2006 